Check for updates

Cite this: RSC Adv., 2022, 12, 3708

Received 27th October 2021

Accepted 13th January 2022

DOI: $10.1039 / \mathrm{d} 1 \mathrm{ra07928j}$

rsc.li/rsc-advances

\title{
Surface interaction between phyllosilicate particles and sustainable polymers in flotation and flocculation
}

\author{
Nahid Molaei, (D) a Mohammad Shoaib, (D) ${ }^{\mathrm{b}}$ John Forster, ${ }^{a}$ Shaihroz Khan, (D) ${ }^{\mathrm{b}}$ \\ Omar Bashir Wani ${ }^{\mathrm{b}}$ and Erin R. Bobicki ${ }^{\star a b}$
}

\begin{abstract}
Non-renewable chemical reagents are commonly used as dispersants or flocculants of phyllosilicate clay particles in several industrial fields such as water/wastewater treatment, food production, papermaking, and mineral processing. However, environmentally benign reagents are highly desired due to the nonbiodegradability and negative impacts of synthetic reagents on aquatic life. In this work, the dispersion and flocculation behavior of sustainable polymers (anionic and cationic biopolymers) sourced from proteins and polysaccharides were studied in serpentine phyllosilicate suspensions using the following bench-scale tests: zeta potential, microflotation, settling and turbidity, and isotherm adsorption using total organic carbon. The anionic polysaccharide-based biopolymer pectin acted as a switchable biopolymer for serpentine. That is, it could switch from being an efficient flocculant at $\mathrm{pH} 7$ to an effective dispersant at $\mathrm{pH} 10$.
\end{abstract}

\section{Introduction}

In the face of grade depletion of ores containing valuable minerals, mineral processing operations must perform energyintensive grinding, which generates significant amounts of fine and ultrafine gangue particles containing phyllosilicate clay minerals. ${ }^{1,2}$ Phyllosilicates are comprised of layered silica tetrahedral sheets and alumina or magnesia octahedral sheets in varying proportions. ${ }^{3-6}$ They can adhere to the surfaces of target minerals during flotation, changing froth stability and rheology and thereby reducing the grade and recovery of valuable minerals. ${ }^{7,8}$ Physical and chemical strategies to counteract the negative effects of phyllosilicate clays have led to overconsumption of some dispersants and depressants, lower pulp solid concentrations, high water consumption, and the need for intense agitation prior to flotation to lower viscosities. Fine phyllosilicate particles are also problematic in mine tailings, thickening operations. Fine and ultrafine charged particles remain suspended in tailings due to repulsive forces between similarly charged particles. Dewatering techniques are required to separate solids and liquids in tailings for water recovery and land reclamation. ${ }^{9,10}$ Coagulation using inorganic salts followed by flocculation with synthetic polymers efficiently removes charged fine particles from water by reducing the repulsive

${ }^{a}$ Department of Materials Science and Engineering, University of Toronto, Toronto, ON, Canada. E-mail: erin.bobicki@utoronto.ca

${ }^{b}$ Department of Chemical Engineering and Applied Chemistry, University of Toronto, Toronto, ON, Canada interparticle forces and neutralizing the particle charge, thus allowing particles to associate and form flocs. ${ }^{11}$

Conventional phyllosilicates mitigation methods in flotation and flocculation threaten environmentally benign, also require high water and energy consumption. To reduce these issues associated with using chemical-based reagents, biodegradable dispersants and flocculants obtained from natural sources (e.g., microorganisms, plants, animals) have been proposed..$^{12,13}$ Application of various types of these "biopolymers" as kaolinite clay flocculants has been comprehensively researched. ${ }^{14-19} \mathrm{~A}$ few studies have reported the effectiveness of various biopolymers to improve flotation and flocculation processes in mineral processing. Huang (2012) found that chitosan (the amine-based polysaccharide) could depress chalcopyrite (copper ore) selectively in the flotation of copper-lead ores. ${ }^{20,21} \mathrm{Li}$ et al. (2015) and Peng et al. (2012) also investigated the chitosan increased the recovery of galena at pH 3-5 as a depressant of chalcopyrite..$^{22,23}$ Li et al. (2015) found that chitosan depressed both molybdenite and chalcopyrite in single mineral flotation at $\mathrm{pH} 6 .{ }^{22}$ Several research studies have examined the effectiveness of the lignosulfonate as a dispersant of kaolinite clay minerals in gold, coal and copper flotation. ${ }^{15,24}$ Liu (2018) also found that lignosulfonate improved the grade of gold ore by dispersing kaolinite particles at pH 9. ${ }^{25}$ Molatlhegi et al. (2017) investigated chitosan as a flocculant of kaolinite particles showed a positive effect on settling of kaolinite particles at $\mathrm{pH}$ range $3-9 .{ }^{18} \mathrm{Y}$. C. Ho $(2010)^{12}$ considered the effect of pectin for flocculation of kaolinite particles, and it was found that $\mathrm{pH} 3$ was the optimum treatment condition for pectin flocculating activity. ${ }^{26}$ Bonilla (2015$2017)^{14}$ studied the effectiveness of proteins (protamine and 
lysozyme) on the dewatering of pulp and paper mill biosludge and found that lysozyme showed higher flocculating activity. ${ }^{14,27,28}$ Previous studies only focused on kaolinite clay particles and the potential of biopolymers to mitigate other types of phyllosilicates in flotation and dewatering has not been evaluated. More importantly, the main mechanism of interaction between biopolymers and clay surfaces is not yet well understood and has not been considered yet.

The present research, for the first time, focuses on the use of polysaccharide- and protein-based biopolymers to mitigate the negative effects of a non-swelling serpentine phyllosilicate $\left(\mathrm{Mg}_{3} \mathrm{Si}_{2} \mathrm{O}_{5}(\mathrm{OH})_{4}\right)$ via zeta potential measurements, flotation, settling, turbidity, and adsorption isotherm using total organic carbon analyzer. Serpentine is a gangue mineral that often presents in high contents in pentlandite (nickel ore) processing circuits. Serpentine is electrostatistically anisotropic and has a 1:1 structure consisting of $\mathrm{Mg}^{2+}$ ions coordinated with oxygen and hydroxyl ions in an octahedral sheet, surrounded by $\mathrm{Si}^{4+}$ ions coordinated with oxygen in a tetrahedral basal plane (Fig. 1). ${ }^{30-32}$ The $\mathrm{Mg}$ basal plane has positive charge at $\mathrm{pH}<10$, whereas the edge and Si basal plane are negatively charged at $\mathrm{pH} 7$ and $10 . .^{33-37}$

\section{Materials and methods}

\subsection{Materials}

High-purity serpentine was obtained from Minerals Unlimited (Ridgecrest, CA, USA). Pentlandite $\left((\mathrm{Fe}, \mathrm{Ni})_{9} \mathrm{~S}_{8}\right)$ from Voisey's Bay Mine (Labrador, Canada) was used in microflotation experiments. X-ray diffraction analysis of serpentine and pentlandite samples indicated that they were of high purity $(<85 \%$ impurities). The mean particle size of serpentine was less than $10 \mu \mathrm{m}$ as determined by a Partica LA-960 laser diffraction particle size analyzer (HORIBA, Toronto, ON, Canada). For zeta potential measurements, a $0.2 \mathrm{wt} \%$ (mass serpentine/volume $18 \mathrm{M} \Omega$ deionized (DI) water) serpentine suspension was prepared. For other tests, a $10 \mathrm{wt} \%$ serpentine suspension was prepared and adjusted to $\mathrm{pH} 7$ and 10 using $0.1 \mathrm{M}$ hydrochloric acid $(\mathrm{HCl})$, $0.1 \mathrm{M}$ sodium hydroxide $(\mathrm{NaOH})$, or soda ash $\left(\mathrm{Na}_{2} \mathrm{CO}_{3}\right)$ from Sigma Aldrich Canada. Six commercially available polysaccharides and protein biopolymers from various sources and with differing charge characteristics and molecular weights were purchased from Sigma Aldrich (Table 1). Their zeta potentials and flocculating performance were compared to Brennfloc polyacrylamide (PAM) from Brenntag (Toronto, ON), which is commonly used as a flocculant in wastewater treatment.
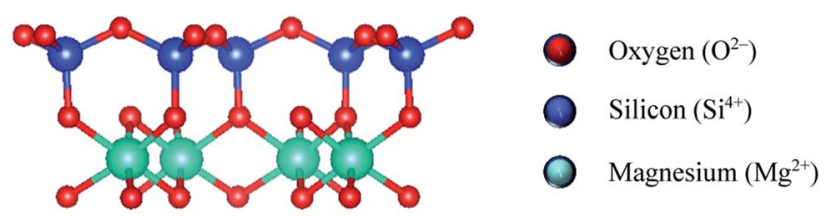

Fig. 1 Serpentine 1:1 structure: silicon tetrahedral layer joined to magnesium octahedral layer. ${ }^{21-23}$

\subsection{Zeta potential measurements}

The zeta potentials of $0.2 \mathrm{wt} \%$ serpentine suspensions in the absence (control) and presence of $0.5 \mathrm{wt} \%$ (mass of polymer/ mass serpentine minerals) polymers (Table 1) (the optimum dosage for biopolymers found by Molaei et al. $2022{ }^{29}$ ) at pH 3, 7, 8.5, and 10 were measured in triplicate using a ZetaCompact Z9000 zetameter (CAD Instruments, Les Essarts le roi, France) with $10 \mathrm{mM} \mathrm{KCl}$ as the background electrolyte solution.

\subsection{Microflotation of pentlandite ores}

Triplicate microflotation tests were performed in $50 \mathrm{~mL}$ glass Hallimond flotation cells. In a beaker, $2.5 \mathrm{~g}$ each of serpentine and pentlandite were dispersed in $45 \mathrm{~mL}$ DI water by magnetic stirring for $30 \mathrm{~min}$. The $\mathrm{pH}$ was adjusted to 10 with soda ash, then $0.5 \mathrm{wt} \%$ of a given polymer was added and conditioned for 2 min prior to addition of $60 \mathrm{~g} \mathrm{t}^{-1}$ potassium amyl xanthate collector (Flottec, Booton, NJ, USA). The collector was conditioned for $3 \mathrm{~min}$, then $40 \mathrm{~g} \mathrm{t}^{-1}$ methyl isobutyl carbinol frother (Flottec) was added for a 2 min conditioning period. Controls were prepared the same way with no biopolymer addition. The dispersed pulp was poured into the microflotation cell at $400 \mathrm{rpm}$ impeller speed. The froth was collected for $30 \mathrm{~s}$. Concentrates and tailings were collected, vacuum filtered through a $0.2 \mu \mathrm{m}$ pore size filter, weighed, and oven-dried at $75{ }^{\circ} \mathrm{C}$ for $24 \mathrm{~h}$ to be prepared for inductively coupled plasma (ICP) analysis to measure component elements.

\subsection{Settling tests}

Triplicate column settling tests were conducted in $500 \mathrm{~mL}$ graduated cylinders using $10 \mathrm{wt} \%$ serpentine suspensions (the initial volume of the slurry was $350 \mathrm{~mL}$ ). The $\mathrm{pH}$ was adjusted to 7 and 10 and $0.5 \mathrm{wt} \%$ biopolymer or PAM (Table 1) was added for the treatments (although this dosage is high for PAM because of its high viscosity, the purpose is only to compare the settling results of biopolymer with PAM at the same condition); no reagents were added for the controls. The effect on flocculating activity of $0.001 \mathrm{M} \mathrm{CaCl}_{2}\left(\mathrm{Ca}^{2+}\right.$ as a divalent cation coagulant) without or in combination with the polymers (PAM and biopolymers) was also investigated. Cylinders were sealed and slowly inverted five times by hand to disperse and homogenize serpentine particles in the solution. The mudline-solid/liquid interface-height was recorded immediately and every $5 \mathrm{~min}$ over a $120 \mathrm{~min}$ period. After $30 \mathrm{~min}$ of each settling test, $15 \mathrm{~mL}$ of supernatant was withdrawn with a syringe, and turbidity was measured using a Hach (London, ON, Canada) 2100Q0 turbidity meter.

\subsection{Adsorption isotherms}

To quantify the mass of water-soluble biopolymers (protamine, lysozyme, and pectin) adsorbed on serpentine particles, total organic carbon (TOC) was used to measure the concentration of polymers on triplicate samples with a TOC-VCPH/CPN analyzer (Shimadzu Corporation, Kyoto, Japan). In this procedure, all forms of carbon in solution are converted to $\mathrm{CO}_{2}$ by combustion. ${ }^{38,39}$ The TOC apparatus was first calibrated using standard 
Table 1 Polymer properties

\begin{tabular}{llll}
\hline Polymer & Sourced from & Molecular weight $\left.(\mathrm{g} \mathrm{mol})^{-1}\right)$ & Type \\
\hline $\begin{array}{l}\text { Cationic } \\
\text { Protamine }\end{array}$ & Salmon & & Protein-based biopolymer \\
$\begin{array}{l}\text { Lysozyme } \\
\text { Chitosan }\end{array}$ & Egg whites & 1523 & $\begin{array}{l}\text { Protein-based biopolymer } \\
\text { Polysaccharide-based biopolymer }\end{array}$ \\
Anionic & Chitin & 14307 & \\
Alginic acid & & $190000-310000$ & Polysaccharide-based biopolymer \\
Pectin & Brown algae & Polysaccharide-based biopolymer \\
Lignin & Apples & 240000 & $\begin{array}{l}\text { Polyphenolic biopolymer } \\
\text { Polyacrylamide }\end{array}$ \\
Wood & Free radical polymerization of acrylamide & 1094 & Synthetic linear polymer
\end{tabular}

solutions of the three biopolymers. Each test used $20 \mathrm{~mL}$ of $10 \mathrm{wt} \%$ serpentine suspension that was adjusted to $\mathrm{pH} 7$ or 10 , conditioned with 500-10 000 $\mathrm{mg} \mathrm{L}^{-1}$ biopolymer, mixed at $150 \mathrm{rpm}$ for $48 \mathrm{~h}$ to achieve an equilibrium state, and centrifuged at $3000 \mathrm{rpm}$ for $5 \mathrm{~min}$. The supernatant was withdrawn and filtered through a $0.2 \mu \mathrm{m}$ pore size syringe filter to yield a clear solution. The mass of biopolymer adsorbed on the serpentine surface $\left(q, \mathrm{mg} \mathrm{g}^{-1}\right)$ was calculated using the following equation.

$$
q=\frac{\left(C_{\mathrm{i}}-C_{\mathrm{e}}\right) \times V}{m}
$$

where $C_{\mathrm{i}}$ and $C_{\mathrm{e}}$ are the initial and equilibrium TOC concentrations in the supernatant, respectively $\left(\mathrm{mg} \mathrm{L}^{-1}\right) ; V$ is the total volume of the serpentine suspension (L); and $m$ is the mass of serpentine in the suspension $(\mathrm{g})$.

\section{Results and discussion}

\subsection{Modification of serpentine surface charge by PAM and biopolymers}

The mean zeta potential of serpentine surfaces in the control was positive from $\mathrm{pH} 3$ to 10 (Fig. 2), suggesting that the $\mathrm{Mg}$ basal plane dominates the surface chemistry. Addition of cationic biopolymers (protamine, lysozyme, and chitosan) had little effect on the zeta potential, except at $\mathrm{pH} 10$ where protamine increased the surface charge of serpentine, indicating strong adsorption of this biopolymer to the serpentine surface. Addition of anionic polymers (alginic acid, pectin, lignin, and PAM) lowered the zeta potential. For alginic acid and lignin, the surface charge reversed from positive to negative. Pectin lowered the zeta potential to near zero at $\mathrm{pH} 3$ and 7 and rendered it negative at $\mathrm{pH} 8.5$ and 10 . Thus, pectin may have the potential to act as a switchable biopolymer, flocculating serpentine at $\mathrm{pH}$ 7 (the target $\mathrm{pH}$ for tailings dewatering) and dispersing it at $\mathrm{pH}$ 10 (the target $\mathrm{pH}$ for nickel ore flotation).

The surface charge and functional groups of biopolymers and serpentine drive the adsorption process. The repulsive force between cationic biopolymers and the positive surface charge of the serpentine $\mathrm{Mg}$ basal plane means that hydrogen bonding between amine groups $\left(\mathrm{NH}_{2}\right)$ in the backbone of cationic biopolymers and the silanol $(\mathrm{Si}-\mathrm{O}-\mathrm{H})$ groups in the structure of serpentine drive adsorption. The mechanism of adsorption of the anionic biopolymers alginic acid, pectin, and lignin is likely charge neutralization and/or hydrogen bonding between $\mathrm{C}=\mathrm{O}$ groups of biopolymers and $\mathrm{OH}$ groups of serpentine. ${ }^{29}$

\subsection{Biopolymers as dispersants in flotation}

Pectin dramatically improved flotation of Ni from pentlandite at pH 10 (Fig. 3): Ni grade and recovery (21 and 98.5\%, respectively) were higher than the control (18.2 and 75\%, respectively). Alginic acid and lignin also improved pentlandite floatability compared to the control, whereas protamine, lysozyme, and chitosan reduced flotation performance. These results were not surprising because the zeta potential results suggested that pectin would be an effective dispersant at $\mathrm{pH} 10$, where the highly negative surfaces of serpentine, especially the silica and edge faces, and negative charge of the biopolymer would contribute to serpentine dispersion. Carboxyl $(\mathrm{COOH})$ functional groups in the polysaccharide backbones of pectin, alginic acid, and lignin could be ionized into $\mathrm{COO}^{-}$, which would increase the repulsive forces, ${ }^{29}$ hence improving $\mathrm{Ni}$ grade and recovery. The microflotation results show that floatability of

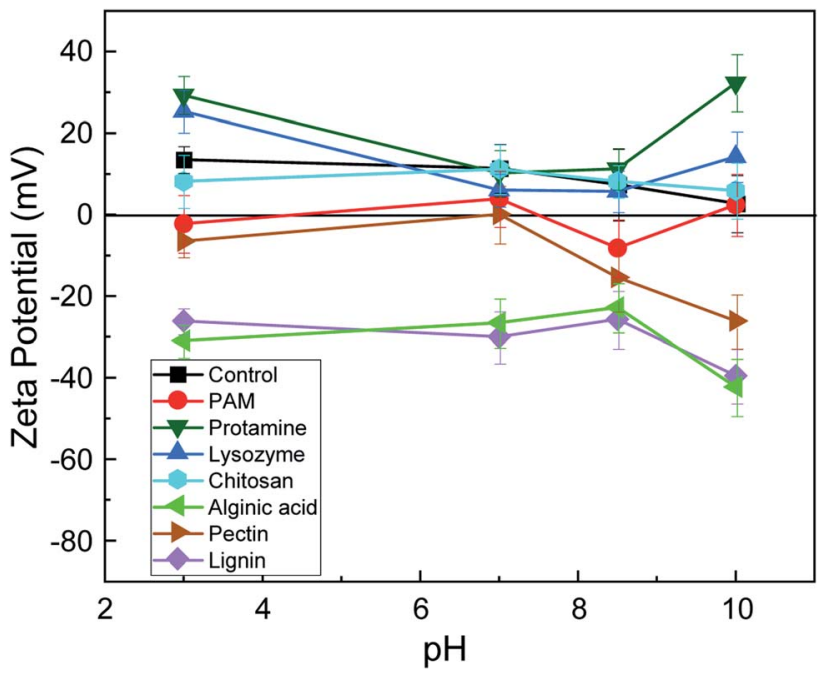

Fig. 2 Mean ( \pm standard deviation) zeta potential of triplicate $0.2 \mathrm{wt} \%$

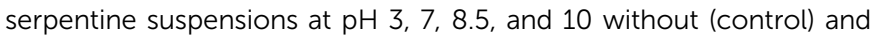
with addition of polyacrylamide (PAM) and six biopolymers. 


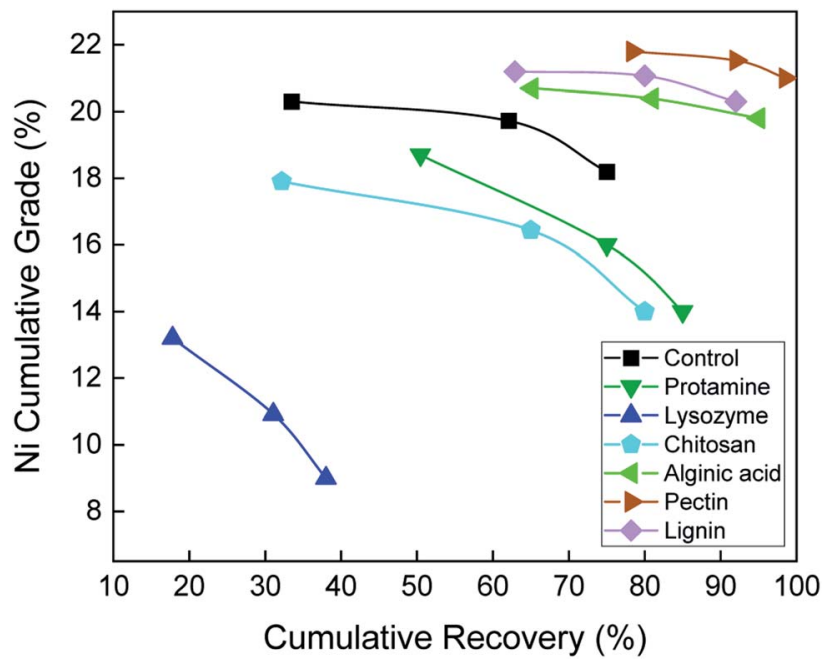

Fig. 3 Nickel grade-recovery curves from microflotation tests on $10 \mathrm{wt} \%$ (1:1 mass ratio) pentlandite-serpentine mixtures without (control) and with the addition of six biopolymers at $\mathrm{pH} 10$.

pentlandite depends on the polymer and surface charge of serpentine at $\mathrm{pH} 10$.

\subsection{Settling behavior}

In the controls, the sediment/water interface (mudline) height declined at a similar rate at pH 7 (Fig. 4a) and pH 10 (Fig. 4b) over the $2 \mathrm{~h}$ settling test. At $\mathrm{pH} 7$, the settling behaviors of serpentine suspensions augmented with lysozyme, chitosan, and alginic acid were similar to the control (Fig. 4a). This is surprising because lysozyme and chitosan are cationic and should have adsorbed to the negative surfaces of serpentine to promote settling at $\mathrm{pH}$ 7. Settling was greatly enhanced by addition of PAM, protamine, and pectin, as indicated by a lower mudline height. At $\mathrm{pH} \mathrm{7}$, the $\mathrm{Mg}$ basal plane of serpentine is positively charged, whereas the edge and Si basal plane are negatively charged. Weak adsorption between protamine and serpentine surfaces could have occurred via charge neutralization because protamine is highly positive at $\mathrm{pH} 7$ due to protonation of amine groups $\left(\mathrm{NH}_{3}{ }^{+}\right)$that have a p $K_{\mathrm{a}}$ of $\sim 12.5 .^{40}$ Adsorption of PAM and protamine also occurs via hydrogen bonding between $\mathrm{NH}_{2}$ groups on the polymer and hydroxyl groups $(\mathrm{OH})$ of $\mathrm{Si}-\mathrm{OH}$ and $\mathrm{Mg}-\mathrm{OH}$ at the edge surface of serpentine. Rapid settling of serpentine in the presence of protamine implies that charge neutralization and hydrogen bonding occur simultaneously. ${ }^{29}$ The negative surface charges of carboxyl groups on pectin $\left(\mathrm{p} K_{\mathrm{a}}<4\right)^{41}$ would be attracted to the positively charged $\mathrm{Mg}$ basal plane by charge neutralization, resulting in flocculation and settling.

At pH 10 and compared to the control, settling was improved the most by PAM, followed by the cationic biopolymers (Fig. 4b). At $\mathrm{pH} 10$, the $\mathrm{Mg}$ basal plane of serpentine has a surface charge near zero, whereas the edge and Si basal plane are negatively charged. Lysozyme $\left(\mathrm{p} K_{\mathrm{a}} \sim 10.5\right)^{42}$ and chitosan $\left(\mathrm{p} K_{\mathrm{a}} \sim 6.1-7\right)^{43}$ are almost neutral, and only when the silica and edge surfaces of serpentine were highly negatively charged did these biopolymers promote settling of serpentine. Settling was hindered by pectin. Pectin was repelled by all the planes, resulting in effective dispersion. The flocculating activity of pectin at $\mathrm{pH} 7$ and dispersing activity at $\mathrm{pH} 10$ suggest pectin is a good candidate as a switchable biopolymer in serpentine processing.

Unlike pectin alone (Fig. 4a), addition of $0.001 \mathrm{M} \mathrm{CaCl}_{2}$ with pectin inhibited settling of serpentine at $\mathrm{pH} 7$ (Fig. 5a). This can be explained by adsorption of $\mathrm{Ca}^{2+}$ on the negatively charged pectin surface preventing pectin adsorption on the positively charged surface serpentine. ${ }^{44-46}$ At $\mathrm{pH} 7$ (Fig. 5a) and 10 (Fig. $5 \mathrm{~b}$ ), $\mathrm{CaCl}_{2}$ promoted serpentine settling in combination with chitosan and protamine, had a negligible effect with lysozyme, and no effect with PAM, alginic acid and lignin.

At $\mathrm{pH}$ 7, the turbidity of serpentine suspensions without $\mathrm{CaCl}_{2}$ was the lowest for pectin and the highest for lignin and alginic acid (Fig. 6a), indicating strong particle aggregation and

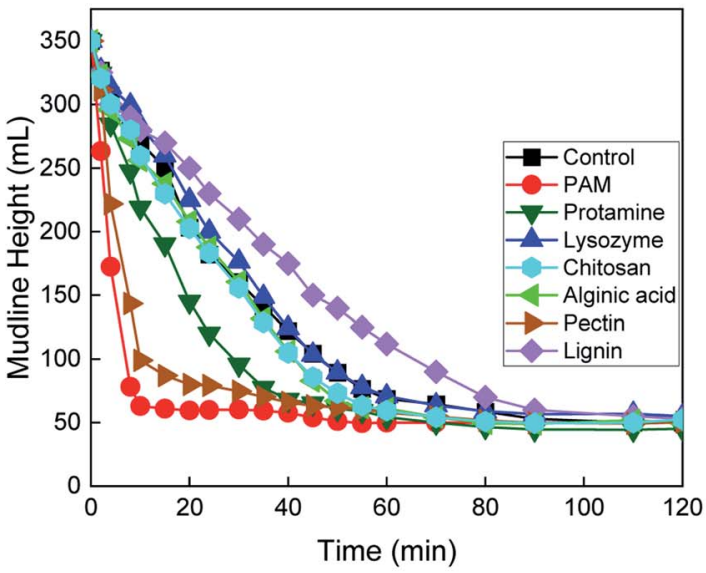

a)

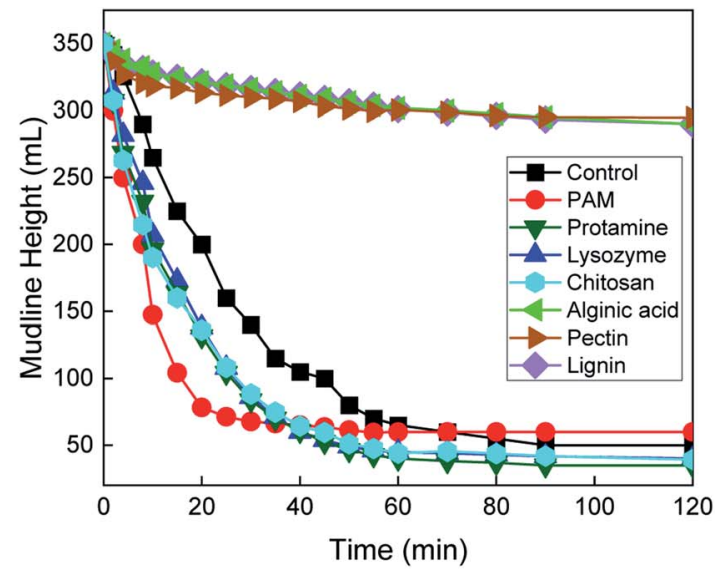

b)

Fig. 4 Mudline height versus time for $10 \mathrm{wt} \%$ serpentine suspensions without (control) or with $0.5 \mathrm{wt} \%$ polyacrylamide (PAM) and six biopolymers at (a) $\mathrm{pH} 7$ and (b) $\mathrm{pH} 10$. 


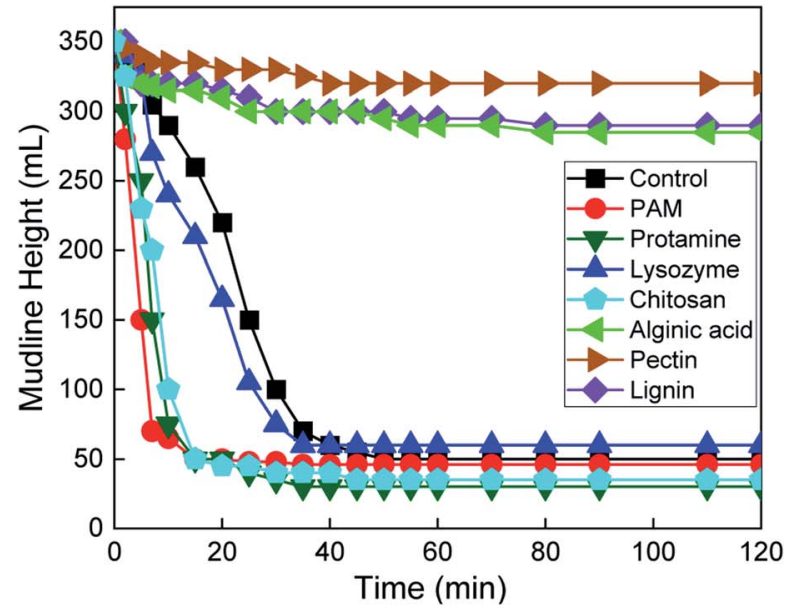

a)

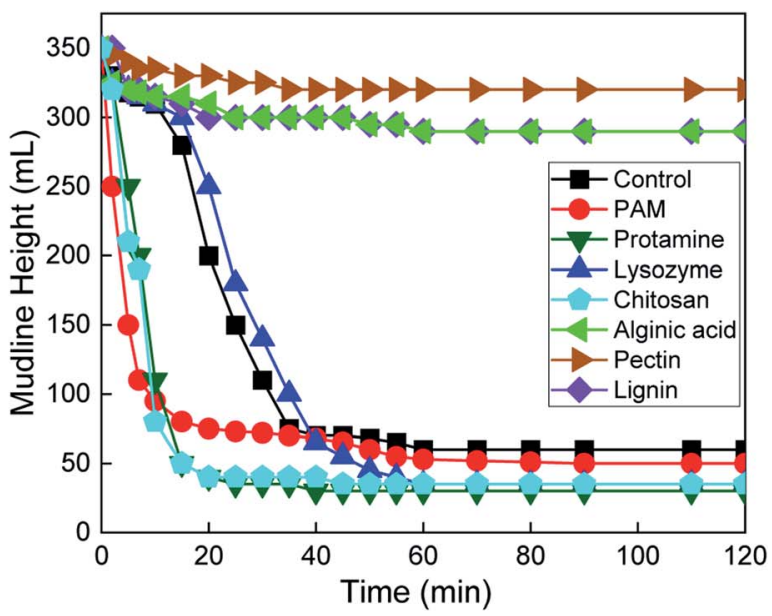

b)

Fig. 5 Mudline height versus time for 10 wt\% serpentine suspensions without (control) or with 0.5 wt\% biopolymer or polyacrylamide (PAM) and $0.001 \mathrm{M} \mathrm{CaCl}_{2}$ at (a) $\mathrm{pH} 7$ and (b) $\mathrm{pH} 10$.

dispersion, respectively. The strong inhibition of the flocculation ability of pectin by $\mathrm{CaCl}_{2}$ is evident in the nearly 10 -fold higher turbidity. Flocculation was less dramatically reduced in the PAM and protamine treatments. $\mathrm{CaCl}_{2}$ increased aggregation for the control and the lysozyme- and chitosan-treated suspensions. At $\mathrm{pH}$ 10, PAM, lysozyme, and protamine were excellent flocculants when used alone, whereas in the presence of $\mathrm{CaCl}_{2}$, PAM, protamine, and chitosan enhanced flocculation (Fig. 6b). Lignin was a very poor flocculant at both $\mathrm{pH} 7$ and 10, with no effect by $\mathrm{CaCl}_{2}$. It is evident that the interactions between biopolymers and $\mathrm{Ca}^{2+}$ at the surface of serpentine are complex and require further investigation to understand the underlying mechanisms.

\subsection{Adsorption isotherm by TOC}

Serpentine had strong adsorption affinity with the cationic biopolymers protamine (Fig. 7a) and lysozyme (Fig. 7b), particularly at $\mathrm{pH} 10$ (higher values for $q$ ), possibly due to formation of large aggregates between serpentine particles. Adsorption also increased with biopolymer dosage, suggesting that adsorption sites on serpentine were not saturated. Hydrogen bonding between $\mathrm{NH}_{2}$ and $\mathrm{COOH}$ groups of proteins and hydroxyl groups of serpentine and/or electrostatic interaction between the cationic biopolymers and the negatively charged surface of the serpentine edge and Si basal planes at $\mathrm{pH}$ 7 contributed to adsorption. ${ }^{29}$ Pectin strongly adsorbed on the serpentine surface only at $\mathrm{pH} 7$ and no equilibrium was

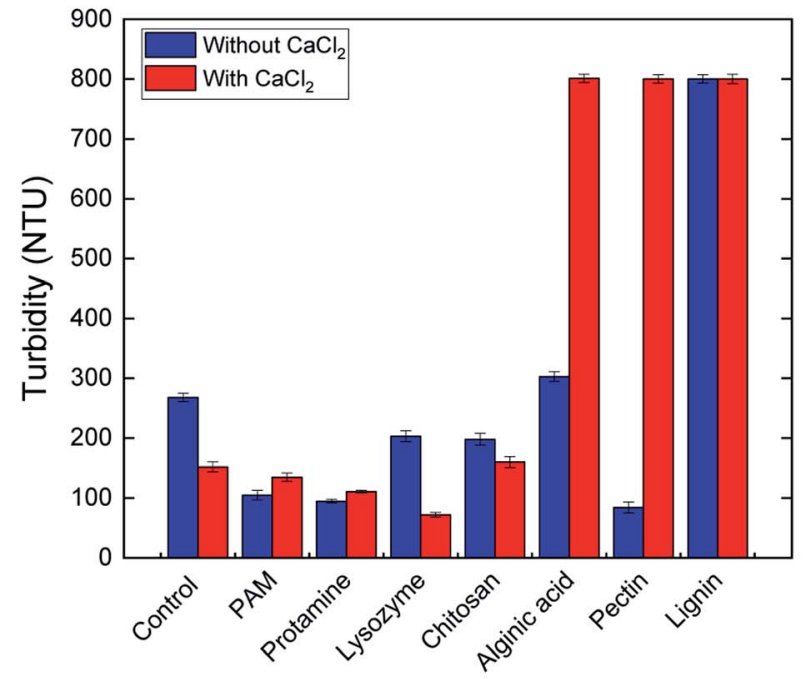

a)

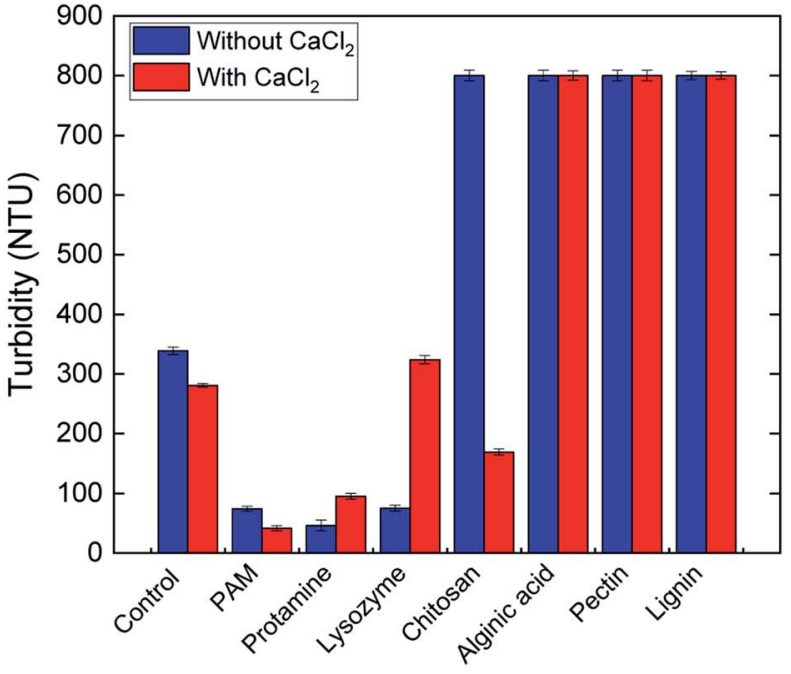

b)

Fig. 6 Turbidity measurements of collected supernatant from settling tests for serpentine with and without $\mathrm{CaCl}_{2} \mathrm{Coagulant}_{\mathrm{at}}(\mathrm{a}) \mathrm{pH} 7$ and (b) $\mathrm{pH} 10$. 


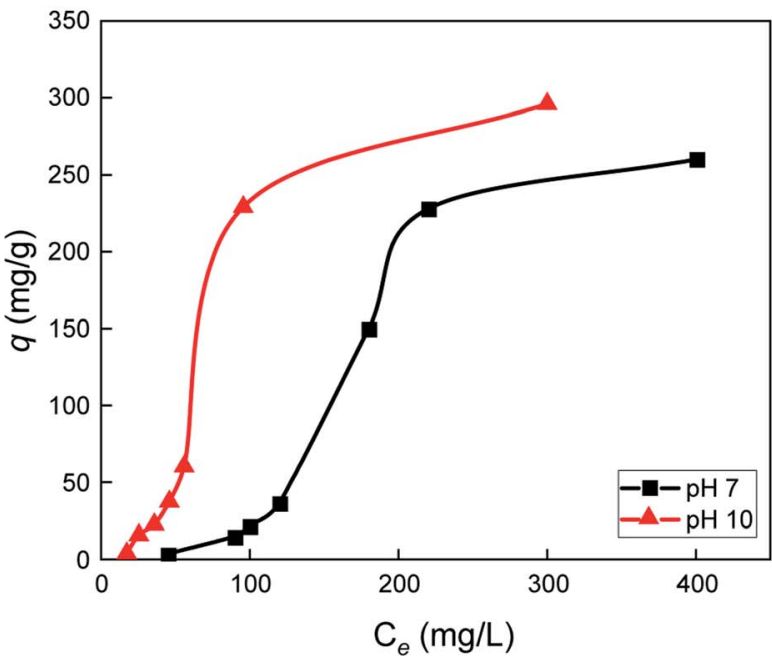

a)

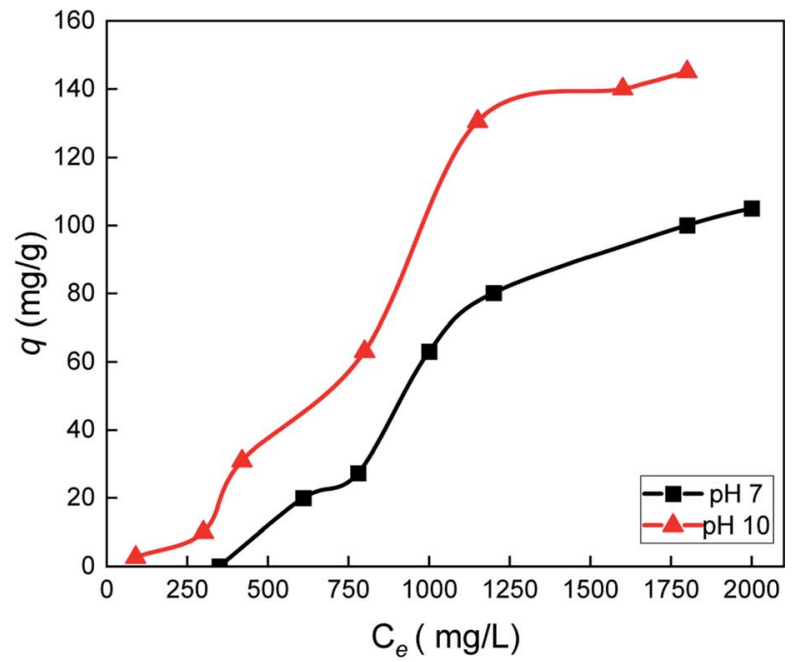

b)

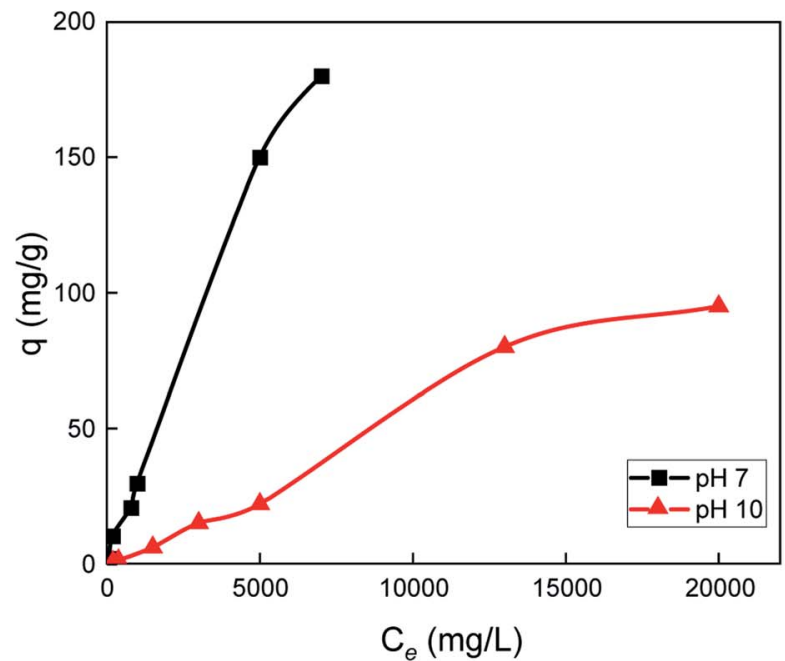

c)

Fig. 7 Adsorption isotherms on serpentine at $\mathrm{pH} 7$ and 10 for (a) protamine, (b) lysozyme, and (c) pectin; q: mass of biopolymer adsorbed on the serpentine surface; $C_{e}$ : equilibrium total organic carbon concentrations in the supernatant.

observed (Fig. 7c). There might be a strong affinity between pectin and serpentine, in agreement with the settling test results in (Fig. 4a), which may be attributed to electrostatic interaction between anionic pectin and the positively charged surface of $\mathrm{Mg}$ basal plane of serpentine.

\section{Conclusions}

This work investigated how six biopolymers with different surface charge and characteristics affected the flocculation and dispersion of serpentine particles at $\mathrm{pH} 7$ and 10 and compared them to PAM, a commonly used synthetic polymer. At pH 7, the zeta potential of pectin approached neutrality, which enhanced the settling rate of serpentine more than did the other biopolymers. At pH 10, however, pectin behaved as a strong dispersant, as indicated by low settling and high turbidity. Protamine also improved serpentine settling at $\mathrm{pH} \mathrm{7,} \mathrm{though}$ not as dramatically as pectin. Protamine, lysozyme, and chitosan improved the settling rate of serpentine compared to the control at $\mathrm{pH}$ 10. Isotherm adsorption experiments confirmed strong adsorption of pectin on serpentine at $\mathrm{pH}$ 7. The main driving mechanism for cationic biopolymers in the presence of negatively charged particles is electrostatic attraction. Divalent cations in the solution made bridges between the negative surface of serpentine and anionic biopolymers. Charge neutralization also played an important role in the adsorption of pectin with serpentine. It can be concluded that pectin acted as a switchable biopolymer for serpentine: it showed flocculating activity at the dewatering $\mathrm{pH}$ of 7 and dispersing activity at the flotation $\mathrm{pH}$ of 10 . Results of this study are applicable not only in mineral processing but also in other industries that have clay issues; pulp and paper mill, wastewater treatment, food production, cement production and ceramics operations. A deeper understanding of biopolymer adsorption mechanism 
using techniques such as atomic force microscopy (AFM) and quartz crystal microbalance with dissipation (QCM-D) is necessary to apply pectin in mineral processing operations and will remain the subject of our future work.

\section{Conflicts of interest}

There are no conflicts to declare.

\section{Acknowledgements}

The authors would like to acknowledge the financial support of Elements of Bio-Mining (EBM): Genomics-Driven Improvements in Mine Operations Project.

\section{References}

1 R. I. Jeldres, L. Uribe, L. A. Cisternas, L. Gutierrez, W. H. Leiva and J. Valenzuela, The Effect of Clay Minerals on the Process of Flotation of Copper Ores-A Critical Review, Appl. Clay Sci., 2019, 170, 57-69, DOI: 10.1016/ j.clay.2019.01.013.

2 G. D. Senior and S. A. Thomas, Development and Implementation of a New Flowsheet for the Flotation of a Low Grade Nickel Ore, Int. J. Miner. Process., 2005, 78, 49-61, DOI: 10.1016/j.minpro.2005.08.001.

3 Y. Wang, Mitigating the Deleterious Effect of Clay Minerals on Copper Flotation, PhD thesis, University of Queensland, 2016, p. 121.

4 B. K. G. Theng, The Clay Minerals, in Developments in Clay Science, Elsevier B.V., 2012, vol. 4, pp. 3-45, DOI: 10.1016/ B978-0-444-53354-8.00001-3.

5 B. Ndlovu, The Effect of Phyllosilicate Mineralogy and Surface Charge on the Rheology of Mineral Slurries, PhD thesis, University of Cape Town, 2013, p. 278.

6 Y. Wang, R. A. Lauten and Y. Peng, The Effect of Biopolymer Dispersants on Copper Flotation in the Presence of Kaolinite, Miner. Eng., 2016, 96-97, 123-129, DOI: 10.1016/ j.mineng.2016.05.010.

7 S. Farrokhpay and D. Bradshaw, Effect of Clay Minerals on Froth Stability in Mineral Flotation: A Review, 26th Int. Miner. Process. Congr. IMPC 2012 Innov. Process. Sustain. Growth - Conf. Proc., 2012.

8 N. Cruz, Y. Peng, S. Farrokhpay and D. Bradshaw, Interactions of Clay Minerals in Copper-Gold Flotation: Part 1 - Rheological Properties of Clay Mineral Suspensions in the Presence of Flotation Reagents, Miner. Eng., 2013, 50-51, 30-37, DOI: 10.1016/j.mineng.2013.06.003.

9 R. Hogg, Flocculation and Dewatering, Int. J. Miner. Process., 2000, 58(1-4), 223-236, DOI: 10.1016/S0301-7516(99)00023$\mathrm{X}$.

10 M. J. Pearse, Historical Use and Future Development of Chemicals for Solid-Liquid Separation in the Mineral Processing Industry, Miner. Eng., 2003, 16(2), 103-108, DOI: $10.1016 / \mathrm{S} 0892-6875(02) 00288-1$.

11 P. Somasundaran and D. Wang, Solution Chemistry: Minerals and Reagents, book, 2006, vol. 220.
12 Y. C. Ho, I. Norli, A. F. M. Alkarkhi and N. Morad, Analysis and Optimization of Flocculation Activity and Turbidity Reduction in Kaolin Suspension Using Pectin as a Biopolymer Flocculant, Water Sci. Technol., 2009, 60(3), 771-781, DOI: 10.2166/wst.2009.303.

$13 \mathrm{H}$. Salehizadeh and S. A. Shojaosadati, Extracellular Biopolymeric Flocculants: Recent Trends and Biotechnological Importance, Biotechnol. Adv., 2001, 19(5), 371-385, DOI: 10.1016/S0734-9750(01)00071-4.

14 T. S. Bonilla and D. G. Allen, Flocculation with Lysozyme: A Non-Enzymatic Application, Can. J. Chem. Eng., 2016, 94(2), 231-237, DOI: 10.1002/cjce.22386.

15 D. Liu and Y. Peng, Understanding Different Roles of Lignosulfonate in Dispersing Clay Minerals in Coal Flotation Using Deionised Water and Saline Water, Fuel, 2015, 142, 235-242, DOI: 10.1016/j.fuel.2014.10.082.

16 Z. Liu, X. Lu, J. Xie, B. Feng and Q. Han, Synthesis of a Novel Tunable Lignin-Based Star Copolymer and Its Flocculation Performance in the Treatment of Kaolin Suspension, Sep. Purif. Technol., 2019, 210, 355-363, DOI: 10.1016/ j.seppur.2018.08.025.

17 S. Wang, L. Zhang, B. Yan, H. Xu, Q. Liu and H. Zeng, Molecular and Surface Interactions between Polymer Flocculant Chitosan g Polyacrylamide and Kaolinite Particles: Impact of Salinity, J. Phys. Chem. C, 2015, 119(13), 7327-7339, DOI: 10.1021/acs.jpcc.5b00739.

18 O. Molatlhegi and L. Alagha, Adsorption Characteristics of Chitosan Grafted Copolymer on Kaolin, Appl. Clay Sci., 2017, 150, 342-353, DOI: 10.1016/j.clay.2017.09.032.

19 L. Alagha, L. Guo, M. Ghuzi, O. Molatlhegi and Z. Xu, Adsorption of Hybrid Polyacrylamides on Anisotropic Kaolinite Surfaces: Effect of Polymer Characteristics and Solution Properties, Colloids Surf., A, 2016, 498, 285-296, DOI: 10.1016/j.colsurfa.2016.03.031.

20 P. Huang, M. Cao and Q. Liu, Using Chitosan as a Selective Depressant in the Differential Flotation of $\mathrm{Cu}-\mathrm{Pb}$ Sulfides, Int. J. Miner. Process., 2012, 106-109, 8-15, DOI: 10.1016/ j.minpro.2012.01.001.

21 P. Huang, M. Cao and Q. Liu, Selective Depression of Pyrite with Chitosan in Pb-Fe Sulfide Flotation, Miner. Eng., 2013, 46-47, 45-51, DOI: 10.1016/J.MINENG.2013.03.027.

22 M. Li, D. Wei, Q. Liu, W. Liu, J. Zheng and H. Sun, Flotation Separation of Copper-Molybdenum Sulfides Using Chitosan as a Selective Depressant, Miner. Eng., 2015, 83, 217-222, DOI: 10.1016/J.MINENG.2015.09.013.

23 P. Huang, M. Cao and Q. Liu, Adsorption of Chitosan on Chalcopyrite and Galena from Aqueous Suspensions, Colloids Surf., A, 2012, 409, 167-175, DOI: 10.1016/ j.colsurfa.2012.06.016.

$24 \mathrm{R}$. Wei, Y. Peng and D. Seaman, The Interaction of Lignosulfonate Dispersants and Grinding Media in Copper-Gold Flotation from a High Clay Ore, Miner. Eng., 2013, 50-51, 93-98, DOI: 10.1016/j.mineng.2013.06.012.

25 S. Liu, X. Chen, R. A. Lauten, Y. Peng and Q. Liu, Mitigating the Negative Effects of Clay Minerals on Gold Flotation by a Lignosulfonate-Based Biopolymer, Miner. Eng., 2018, 126, 9-15, DOI: 10.1016/j.mineng.2018.06.021. 
26 Y. C. Ho, I. Norli, A. F. M. Alkarkhi and N. Morad, Characterization of Biopolymeric Flocculant (Pectin) and Organic Synthetic Flocculant (PAM): A Comparative Study on Treatment and Optimization in Kaolin Suspension, Bioresour. Technol., 2010, 101, 1166-1174, DOI: 10.1016/ j.biortech.2009.09.064.

27 S. Bonilla, H. Tran and D. G. Allen, Enhancing Pulp and Paper Mill Biosludge Dewaterability Using Enzymes, Water Res., 2015, 68, 692-700, DOI: 10.1016/j.watres.2014.10.057.

28 S. Bonilla and D. G. Allen, Cationic Proteins for Enhancing Biosludge Dewaterability: A Comparative Assessment of Surface and Conditioning Characteristics of Synthetic Polymers, Surfactants and Proteins, Sep. Purif. Technol., 2018, 191, 200-207, DOI: 10.1016/J.SEPPUR.2017.08.048.

29 N. Molaei, S. Chehreh Chelgani and E. R. Bobicki, A Comparison Study between Bioflocculants and PAM for Dewatering of Ultrafine Phyllosilicate Clay Minerals, Appl. Clay Sci., 2022, 218, 106409, DOI: 10.1016/ j.clay.2022.106409.

30 B. Feng, Y.-P. Lu, Q.-M. Feng, P. Ding and N. Luo, Mechanisms of Surface Charge Development of Serpentine Mineral, Trans. Nonferrous Met. Soc. China, 2013, 23, 11231128, DOI: 10.1016/S1003-6326(13)62574-1.

31 G. Pan, G. Zhang, Q. Shi and W. Chen, The Effect of Sodium Alginate on Chlorite and Serpentine in Chalcopyrite Flotation, Minerals, 2019, 9(3), 196, DOI: 10.3390/ $\min 9030196$.

32 T. Long, X. Huang and W. Xiao, The Effect of Surface Charge on the Separation of Pyrite from Serpentine by Flotation, Minerals, 2019, 9(10), 629, DOI: 10.3390/min9100629.

33 E. R. Bobicki, Q. Liu and Z. Xu, Effect of Microwave PreTreatment on Ultramafic Nickel Ore Slurry Rheology, Miner. Eng., 2014, 61, 97-104, DOI: 10.1016/ j.mineng.2014.03.025.

34 V. Gupta and J. D. Miller, Surface Force Measurements at the Basal Planes of Ordered Kaolinite Particles, J. Colloid Interface Sci., 2010, 344(2), 362-371, DOI: 10.1016/ j.jcis.2010.01.012.

35 J. Liu, L. Sandaklie-Nikolova, X. Wang and J. D. Miller, Surface Force Measurements at Kaolinite Edge Surfaces Using Atomic Force Microscopy, J. Colloid Interface Sci., 2014, 420, 35-40, DOI: 10.1016/j.jcis.2013.12.053.
36 D. Yang, L. Xie, E. Bobicki, Z. Xu, Q. Liu and H. Zeng, Probing Anisotropic Surface Properties and Interaction Forces of Chrysotile Rods by Atomic Force Microscopy and Rheology, Langmuir, 2014, 30(36), 10809-10817, DOI: 10.1021/la5019373.

37 X. Yin, L. Yan, J. Liu, Z. Xu and J. D. Miller, Anisotropic Surface Charging of Chlorite Surfaces, Clays Clay Miner., 2013, 61(2), 152-164, DOI: 10.1346/CCMN.2013.0610212.

38 E. A. López-Maldonado, M. T. Oropeza-Guzman, J. L. JuradoBaizaval and A. Ochoa-Terán, Coagulation-Flocculation Mechanisms in Wastewater Treatment Plants through Zeta Potential Measurements, J. Hazard. Mater., 2014, 279, 1-10, DOI: 10.1016/j.jhazmat.2014.06.025.

39 K. Cooper, Total Organic Carbon Analysis, BioPharm, 2001, 14(12 Suppl.), 49-50.

40 C. Pascu, Å. Ljungh and T. Wadström, Staphylococci Bind Heparin-Binding Host Growth Factors, Curr. Microbiol., 1996, 32, 201-207, https://pubmed.ncbi.nlm.nih.gov/ 8867461.

41 L. Flutto, PECTIN | Properties and Determination, in Encyclopedia of Food Sciences and Nutrition, Elsevier, 2003, pp. 4440-4449, DOI: 10.1016/b0-12-227055-x/00901-9.

42 M. R. Salton, The Properties of Lysozyme and Its Action on Microorganisms, Bacteriol. Rev., 1957, 21(2), 82-100, DOI: 10.1128/mmbr.21.2.82-100.1957.

43 M. M. Amiji, Pyrene Fluorescence Study of Chitosan SelfAssociation in Aqueous Solution, Carbohydr. Polym., 1995, 26(3), 211-213, DOI: 10.1016/0144-8617(94)00095-B.

44 J. C. Crittenden and W. H. Montgomery, Chapter 9: Coagulation and Flocculation, MWH's Water Treat. Princ. Des., 2012, DOI: 10.1016/B978-0-444-52734-9.50012-8.

45 P. Mpofu, J. Addai-Mensah and J. Ralston, Investigation of the Effect of Polymer Structure Type on Flocculation, Rheology and Dewatering Behaviour of Kaolinite Dispersions, Int. J. Miner. Process., 2003, 71(1-4), 247-268, DOI: 10.1016/S0301-7516(03)00062-0.

46 A. Shakeel, Z. Safar, M. Ibanez, L. van Paassen and C. Chassagne, Flocculation of Clay Suspensions by Anionic and Cationic Polyelectrolytes: A Systematic Analysis, Minerals, 2020, 10(11), 1-24, DOI: 10.3390/min10110999. 